\title{
Role of social protection in disaster management in Sri Lanka
}

\author{
Kanchana Wickramasinghe \\ Institute of Policy Studies, 100/20, Independence Avenue, Colombo 07
}

\begin{abstract}
Sri Lanka has witnessed a striking increase in both the frequency and intensity of natural disasters over the last few decades. Natural disasters have caused human, physical, financial and environmental losses and made substantial impacts on the economy of Sri Lanka. The impacts of natural disasters are not homogeneous across various segments of the society. The distribution of impacts depends on the degree of physical vulnerability of a particular region to natural disasters and the socio-economic vulnerability. The poor, especially those who are dependent on natural resources for their livelihoods, such as farmers and fishermen are highly vulnerable to the negative impacts of natural disasters. Given the significant economic costs of natural disasters, disaster management issues have received high policy priority. Apart from reducing the physical vulnerability of the population, social protection systems do have an important complementary role in minimizing the effects of natural disasters. Sri Lanka is well-known to have an extensive social protection system. However, the degree to which the present system provides protection against natural disasters remains unexplored. Thus, the present study assesses the degree of protection provided by the present social protection system in Sri Lanka against natural disasters, identifies gaps in doing so, and thereby suggests suitable recommendations to strengthen the system.
\end{abstract}

The study reveals that the present social protection system in Sri Lanka is not adequate to address the socio-economic vulnerability due to external shocks created by natural disasters. All the disaster-related socio-economic measures in place are highly skewed towards immediate relief, whereas long-term economic well-being of the disaster vulnerable groups has received minor attention. The disaster insurance schemes are also not properly developed and the existing crop insurance schemes show a low coverage. Microfinance services also do not adequately respond to the needs of the disaster vulnerable groups. The study recommends the need for making reforms in the existing programmes, thereby to suggest better protection against natural disasters without introducing new measures and increasing the complexity of the system.

Keywords: Natural disasters, poverty, social protection, Sri Lanka, vulnerability

\section{INTRODUCTION}

Sri Lanka has been experiencing an increased frequency and complexity of natural disaster incidents over the last few decades. For a developing country like Sri Lanka, an additional burden is posed on the economy by regular occurrence of natural disasters. Disaster-related vulnerabilities are now high in the agenda due to the impacts of global climate change. Scientific evidence finds that climate change will further increase the frequency and the intensity of disasters. The disasters cause loss of lives, damage to properties, impacts on livelihoods, etc. which pose significant implications on economic growth. However, the impacts of natural disasters are not the same across all segments of the society, thereby worsening the existing economic disparities. Particularly the poor are more vulnerable to such shocks since, by definition, the poor lack assets, have limited accessibility to opportunities, and poor connectivity to the social networks. On the other hand, the types of assets that the poor possess may be too limited or not sufficiently diversified to protect them against the negative effects caused by disasters. Thus, poverty itself is considered as a form of vulnerability (Tandon and Hasan, 2005). This calls for the need for having effective risk management tools in place.

Effects of natural disasters are not merely dependent on the nature or the magnitude of the disaster, but also, on the mitigation and prevention strategies, the level of 
preparedness for the calamity and socio-economic status of the households or communities who are under the risk of disasters. Thus, disaster management systems should encompass measures to reduce both physical vulnerability and socio-economic vulnerability against disasters. Even though reducing physical vulnerability is seen as the cheapest option to manage disasters, socio-economic security systems still do have a very vital role in minimizing the impacts of a disaster. This does not mean that social protection instruments alone should be considered, but that they serve an important complementary role (Vakis, 2006) in the general framework of disaster risk management.

In this backdrop, disaster risk management has to be an integral part of the overall social protection system. As the poor are highly vulnerable to natural disasters, the poverty reduction strategies also should have elements of disaster risk reduction. Disaster-related social protection instruments would help prevent disaster victims falling into poverty and ensure at least a minimal level of wellbeing during and after disasters. However, in the case of Sri Lanka, there is little or no research conducted in relation to disaster risk management and social protection. The paper intends to shed light on the said research gap. Accordingly, the overall objective of the paper is to explore the extent to which Sri Lanka's social protection system addresses the issues of those who are vulnerable to natural disasters. It reviews the social protection programmes which are already in place, with the aim of identifying gaps that need to receive policy attention. Finally, the paper outlines suitable policy recommendations to improve the present social protection system of the country in order to provide better security during natural disaster situations by effectively addressing the disaster related socio-economic implications.

\section{CONCEPTUAL FRAMEWORK: SOCIAL PROTECTION IN DISASTER MANAGEMENT}

Disaster vulnerability is a multifaceted concept. The term vulnerability denotes the exposure to uninsured risk leading to a socially unacceptable level of wellbeing (Hoogeveen et al., 2004). The dimensions of vulnerability include exposure, sensitivity and resilience towards a risk. The first dimension of vulnerability, 'exposure' is linked to both occurrence of a disaster and the location. 'Sensitivity' is related to the socio-economic and ecological conditions of a particular group. Finally, the extent to which communities have coping capacities and adaptation strategies which help them survive under stress, recover and enact change to prevent future disaster risks, is termed as 'resilience'. Social protection systems are meant to assist individuals, households and communities to better manage risks and to provide support to the critically poor (Holzmann and Jorgensen, 2000). Natural disasters are a kind of risk that people have to face and these fit 'naturally' within the social risk management framework in any country (Vakis, 2006).

The new framework of social risk management system introduced by Holzmann and Jorgensen (2000) identifies three main building blocks, namely, risk management strategies, risk management arrangements by level of formality and the actors in risk management. The risk management strategies consist of prevention, mitigation and coping strategies. Preventive strategies help to reduce the probability of a downward risk prior to the occurrence of a disaster. This may include policies relevant to public health, education, training and environment within a social protection framework. Mitigation strategies are designed to decrease the potential impacts of future downward risk before they occur. This includes income diversification measures, insurance mechanisms, etc. Coping strategies are designed to help the affected groups to relieve the impacts of the disasters once they occur.

Based on the level of formality risk management strategies can fall into three categories namely, informal arrangements, market-based arrangements and publicly mandated or provided arrangements. The actors of a social protection framework include individuals/ households, communities, NGOs, market institutions, governments and international institutions. Individuals and communities have a lot of private information and thus, provide a platform for the creation of informal mechanisms to manage disaster risks. Whereas, market institutions have to depend on public information and therefore, have to face the problems of moral hazards and adverse selections. The government can play several important roles in reducing disaster risks such as implementation, facilitation and monitoring of risk prevention policies, provision of risk management instruments and provision of social safety nets.

In addition, an efficient and effective disaster risk management system should consider the elements of natural disasters (Vakis, 2006) and the degree of vulnerability. The elements of a natural disaster including the type of disaster, probability of occurrence, localization and extent, should essentially be considered in designing the strategies. It should also be differentiated whether the disasters are sudden one-time events or slow events which develop over time. 
An effective social protection system should address the specific socio-economic implications resulting from natural disasters. The next section of this article identifies the nature of impacts of natural disasters and their implications on socio-economic vulnerabilities.

\section{SOCIO-ECONOMIC IMPLICATIONS OF NATURAL DISASTERS}

Although the overall costs of natural disasters are difficult to measure in monetary terms, the evidence shows that the impacts are substantial. Thus, the negative impacts could retard economic performance of the country. For instance, in the year 2004 Sri Lanka experienced a severe drought and flood situation which led to deceleration the country's economic growth from 6 percent of growth rate in 2003 to 5.4 percent (Central Bank of Sri Lanka, 2004).

Natural disasters have significant impacts on poverty. Like in many other developing countries, in Sri Lanka also, poverty is basically a rural phenomenon (Datt and Gunewardena, 1997) where 90 percent of the poor are living in rural areas.
Most of the rural poor are dependent on agriculture which is greatly affected by natural disasters in Sri Lanka. It is estimated that more than 33 percent of the workforce (Department of Census and Statistics, 2003) and 70 percent of the population depend on agriculture directly or indirectly for their income.

The poverty incidence among agricultural workers is around 24 percent which is significantly higher than the poverty rate of non-agricultural workers which is around 16 percent (World Bank, 2007). The alarming feature is that, in Sri Lanka 84 percent of the informal sector workers are agricultural workers and they are not covered by the government's formal social protection schemes. The World Bank Poverty Assessment (2007) reveals that a high concentration of population in Sri Lanka hovers around the poverty line, so that even a small shock can cause a higher poverty incidence. However, the poor has been exclusively the target of most of the poverty alleviation programmes. One of the failures of antipoverty policies of Sri Lanka is that the non-poor who are at risk of falling into poverty are not targeted (IPS, 2002). Since frequency and severity of natural disasters have been increasing over time, they can have significant impacts on poverty in the rural areas.

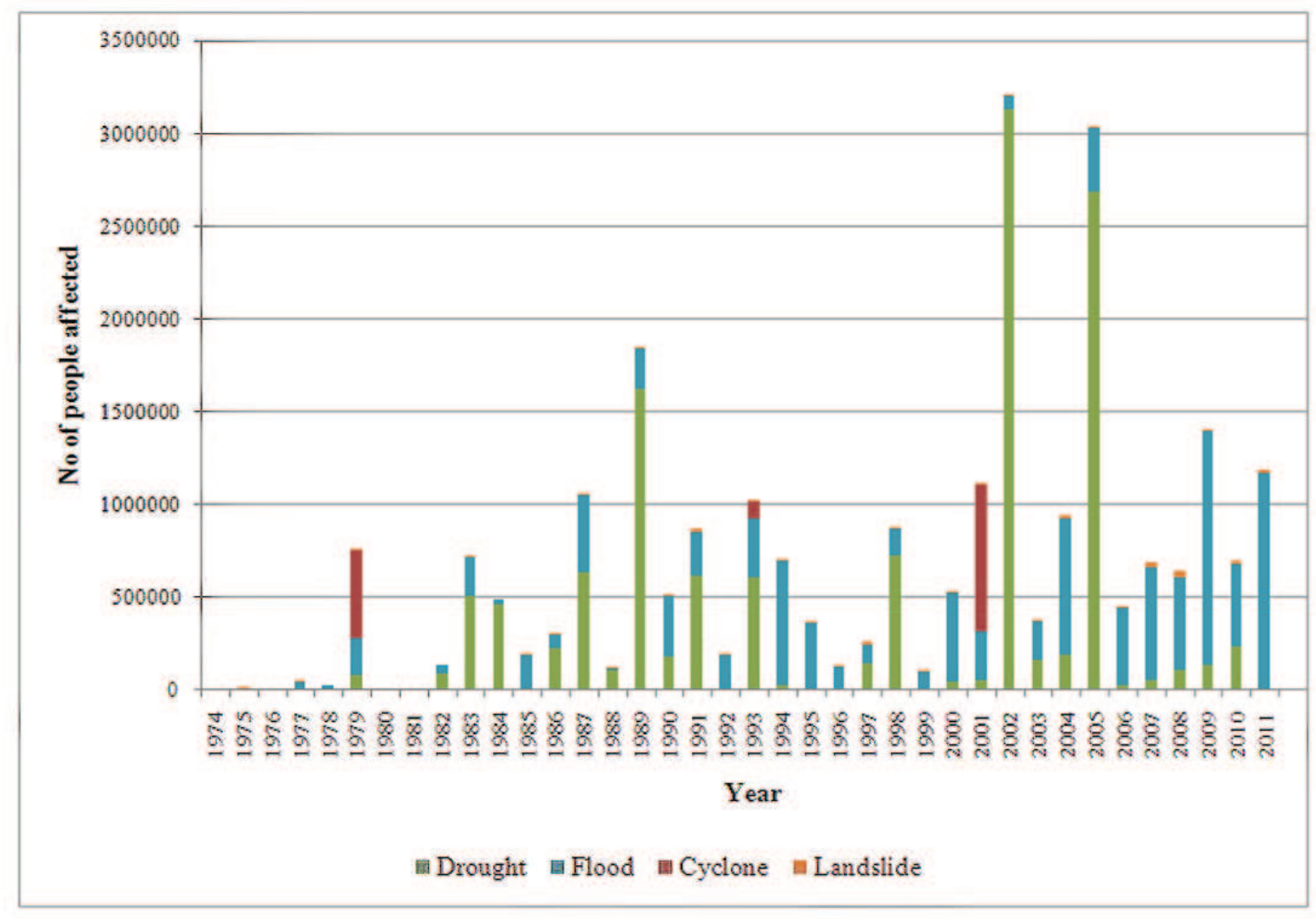

Figure 1: Number of people affected due to natural disasters in Sri Lanka

Source: Author's illistration using data from www.desinverntar.lk 
The coping strategies adopted by farmers during drought and flood situations lead themselves to move into greater poverty. A study carried out by Senaka-Arachchi (1998) in the Dry Zone of Sri Lanka reveals that 35 percent of the surveyed households have cut down meals and 75 percent of households have reduced the variety and quality of food consumed. This would possibly have significant impacts on the nutritional status of household members including the children. The household assets such as furniture, livestock, bicycles and jewellery are also being sold to cope with shocks. Availability of fewer non-farm income generating opportunities worsen the economic situation of the households. In the case of the Dry Zone of Sri Lanka, the principal way of supplementing household income at times of drought is wage labouring within and outside the village (SenakaArachchi, 1998). Large increases in the head count ratio were observed in the districts which are affected by the drought during the last decade. These districts include Moneragala, Ratnapura, Matale and Puttalam (World Bank, 2007). The coping strategies adopted by the coastal communities following the tsunami include reduced food consumption, selling assets and sending more household members to work (Arunatilake et al., 2006) which will ultimately affect the level of well-being of the victims. In this backdrop, provision of social protection seems to be a wise intervention to enable them to manage risks of disasters.

The analysis reveals the fact that natural disasters increase the existing vulnerabilities and pose additional vulnerabilities. Further, the available disaster coping strategies are not adequate to address the existing vulnerabilities. In this context, the social protection system has an important role to play to enable vulnerable groups to effectively face the impacts of natural disasters. The extent to which the existing social protection system addresses the aspects of disaster related vulnerabilities is assessed in the following section.

\section{REVIEW OF SOCIAL PROTECTION SYSTEM IN SRI LANKA}

Sri Lanka is well known to have an extensive social security system, which encompasses income supplementary programmes for the poor, old age insurance, universal access to education and health facilities, etc. It is estimated that nearly 55 percent of the labour force is covered by the government social security schemes such as pensions and other old age benefits and also some life insurance, health and disability cover (IPS, 2006). As per the continued commitment of the Sri Lankan government in the provision of universal education and health services for all, it has reached higher levels of human development. The section assesses the role of existing social protection programmes in managing natural disaster risks in Sri Lanka. Various disaster coping and disaster mitigation strategies are discussed in the subsequent sub-sections.

\section{Disaster coping strategies}

Disaster coping strategies are important in providing assistance for vulnerable groups to avoid consumption shortfalls and meet their immediate basic needs on the aftermath of a disaster. However, an effective disaster relief mechanism should identify the needs of the victimized groups and genuine beneficiaries. Relief should also respond to capacities of the communities and their aspirations. The interventions could be either in-kind transfers or cash transfers. In the case of slow disasters the informal relief mechanisms work well through mutual assistance, but this is not possible with sudden disasters such as floods, tsunami, etc.

\section{In-kind transfers}

In Sri Lanka provisions are made under two categories namely, widespread disaster relief and casual disaster relief. Floods, droughts, cyclones, land slides, plagues, inundation by sea, man-made disasters and fire are categorized as widespread disasters. Casual disasters include minor damages to property, damages to crops by wild elephants and fire. However, the recipients must be below a certain income level to be eligible for entitlement to relief under widespread and casual disasters. Funeral expenses, relief for medical treatment, relief for damaged houses, recovery payments for small scale selfemployment enterprises that are completely damaged as a result of a disaster, relief for crop damages which are not covered by any other insurance scheme, provision of kitchen utensils are the kinds of relief provided in cases of both casual and widespread disasters. In addition, at widespread disasters, the affected and needy people are provided with cooked meals. If they need further assistance, dry rations are provided when the displaced people are able to prepare their meals personally.

The 2004 tsunami experience showed that relief and recovery activities in Sri Lanka took place in an uncoordinated manner. Following tsunami, a large number of NGOs, private society organizations and CBOs volunteered, providing relief services to the tsunami victims soon after the catastrophe. Since the relief activities were not coordinated well and due to a lack of 
cooperation between the parties, the relief distribution showed high inequalities. The Disaster Management Centre (DMC) was established in 2005 and now the DMC is mandated to undertake planning, coordination and implementation of disaster management activities of the country.

\section{Cash transfers}

Cash transfers can play a useful role in the case of disasters by several means. They provide the victims with the highest flexibility in terms of how to use them. Thereby, the recipients are prevented from using harmful coping strategies such as reduction of consumption, etc. A cash grant programme was initiated in the aftermath of the tsunami with assistance from the World Bank. The affected households were given four instalments of Rs. 5,000 per family. The estimated total cost was Rs. 4 billion. Targeting errors were observed in the programme where a significant number of non-eligible households benefited.

\section{Disaster mitigation strategies}

\section{Crop insurance in Sri Lanka}

Insurance falls into a market based type of risk mitigating instrument. At a time of a calamity, disaster insurance provides compensation by pooling risks in exchange for a premium payment. A crop insurance scheme is being implemented by the Agriculture and Agrarian Insurance Board (AAIB). It is aimed to protect those affected against loss of income due to natural hazards. It covers 14 major crops and livestock, and post-harvest losses in those areas. The protection is provided against the losses caused by drought, inadequate water, excess water, floods, pest attacks, disease outbreaks and wild animal attacks. The insurance is based on the type of crop, mode of irrigation (rain-fed, large irrigation schemes, small irrigation schemes) and the degree of risk to a particular natural disaster. The enrollee has to pay a certain percentage of the insurance as the premium, depending on the magnitude of the risk, where the rates are 5, 6 and 8 percent for low risk, medium risk and high risk areas, respectively. The compensation payment depends on the premium paid by the farmer. In the case of the paddy insurance scheme, the farmers should adhere to the cropping calendar and should have planted recommended varieties of paddy. The crop loss should be a minimal of 20 percent for being entitled for compensation and the losses are determined based on the standard level of harvest for a given area. The schemes are being implemented through district level offices of the AAIB, with the assistance of field officers, agricultural research and development officers.

The performance of the scheme so far, shows that it functions below the required level. The scheme seems to be highly inefficient in reaching its target group. As shown in Figure 2, it shows a very low enrolment ratio which is mainly due to the inability of farmers to pay premiums. In addition, only those whose crops are at a high risk of being affected by the above mentioned natural calamities tend to be enrolled, causing the problem of 'adverse selection'. Besides, getting the crops insured has become a necessity when farmers apply for agricultural loans from the banks. Thus, in addition to most vulnerable farmers, the loan applicants also tend to buy insurance. As a result, the insurance business has been costly and the AAIB does not seem financially viable for the successful implementation of the programme. Recently, the AAIB has excluded some of the crops from the scheme which are at high risk of being affected.

A private sector company recently entered the field of crop and livestock insurance, and is implementing a separate scheme, which shows common characteristics with the government programme. The income from crop insurance premium accounts only for a small part of their overall insurance business. Purchasing crop insurance from the company is a prerequisite for farmers if they are to apply for agricultural loans from the company. However, the company does not undertake any ground level promotion activities, to make the scheme popularized. Therefore, in order to retain the membership, customer care is highly emphasized during the claim process. The company is bound to pay the insurance to the farmers, most probably within 2 days after submitting a claim, if the required criteria for compensation are fulfilled; otherwise it takes less than 2 weeks. Claims are usually submitted through the banks. The cheques are normally sent to the member through the bank. During the period of 1998 - 2009, both crop insurance schemes on average (AAIB and private company) have covered only 4.23 percent of the total area of cultivated paddy (Figure 2). The discussion follows the fact that the scheme requires a strong ground level activity to increase membership.

\section{Insurance for wild elephant attacks}

Wild elephant attacks were recognized as a burning problem for rural agricultural communities living near natural forests in some parts of the country. Rising population poses pressure on natural forest covers and wild elephants get restricted/combined to small forest plots. The elephants come to cultivated areas in search 
of food and water and destroy the crops, houses and other private property of the farming communities, intensifying the problems faced by them.

Hence, human-elephant conflict in turn has significant impacts on the agriculture-dependent poor. An innovative step forward is that a private insurance company has come up with an insurance policy to provide coverage against losses caused by 'human-elephant conflict' in 2007.

The policy aims at helping communities who are at the risk of wild elephant attacks, as well as conserving elephants and safeguarding their natural habitats. The scheme provides benefits in the case of death or permanent disablement of the insured, death or permanent disablement of the spouse, damages to crops insured and damages to insured homes. Twenty percent of profits of the scheme are intended for elephant conservation activities. The policy is integrated with other insurance activities carried by the company.

\section{Microfinance}

Microfinance encompasses several measures and instruments provided for the poor who do not have access to financial resources most of the time.
The role of microfinance is recognized to be vital during natural disaster risks, and microfinance has to be an integral component of a comprehensive disaster risk management strategy (Mechler, Linnerooth-Bayer and Peppiatt, 2006). The outreach of the formal credit institutions in providing credit facilities in the rural sector in Sri Lanka is less than 19 percent of the credit requirements. Due to easy access and minimal requirement of documentation, households seek credit facilities offered by informal lenders who include landlords, shopkeepers and traders, friends and relatives, at a high interest rate (Abeyratne Bandara, 1997). However, outreach of the microfinance services in the remote rural areas is constrained by lack of infrastructure facilities, limited opportunities available for non-agricultural activities and increased cost of business operations including costs on microfinance services as a result of insufficient infrastructure (Tilakaratna, Wickramasinghe \& Kumara, 2005).

It has been common belief that microfinance services have reached the poorest of the poor though the majority is from non-poor vulnerable groups (Tilakaratna et al., 2005). The poorest groups use microfinance facilities for consumption purposes mostly, whereas non-poor households use them for income generating activities.

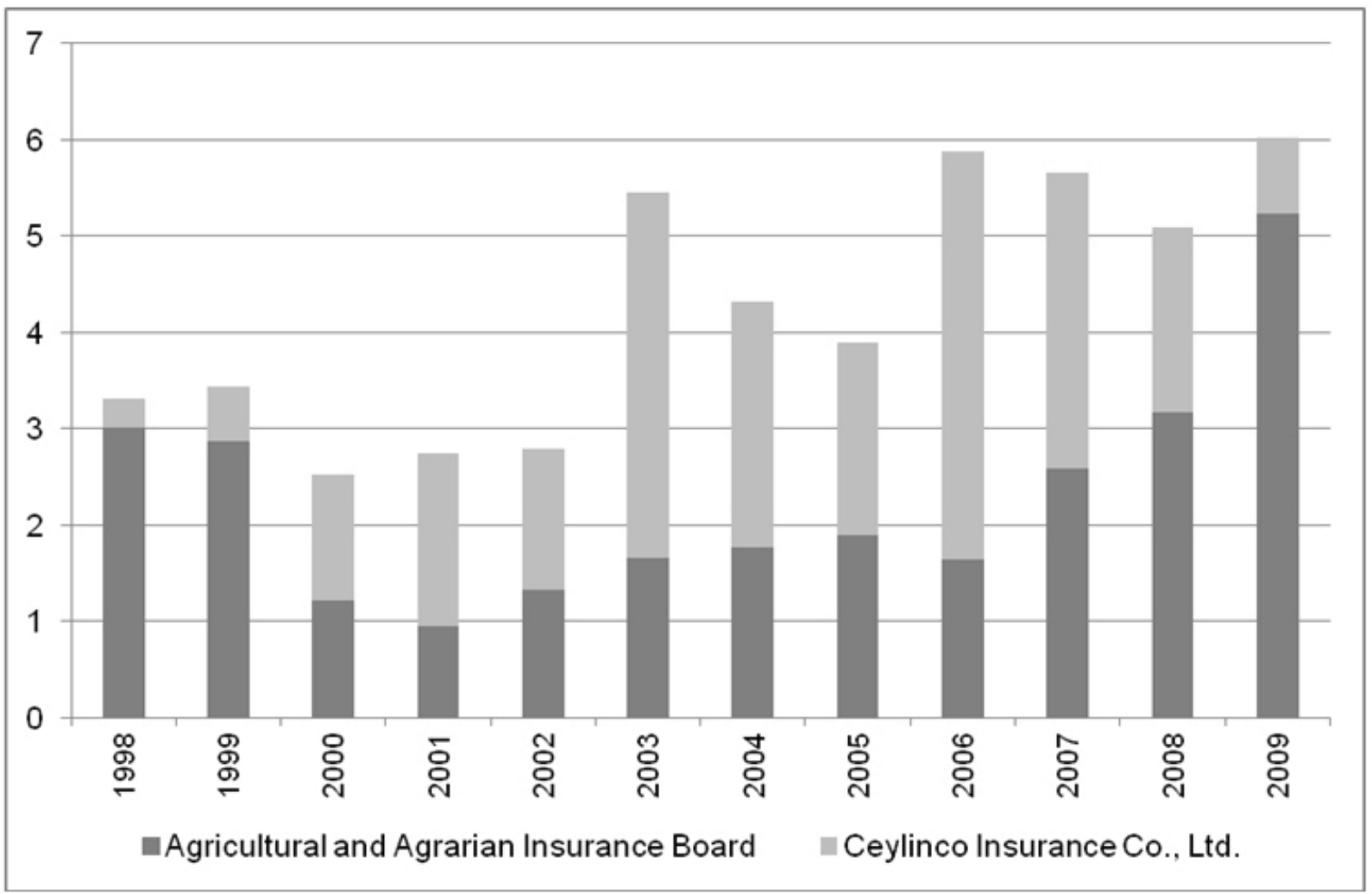

Source: Central Bank Annual Report 2009 and 2010

Figure 2: Percent area of paddy extent covered by crop insurance schemes 
However, microfinance in Sri Lanka has helped the poor to increase income and assets and also to uplift the habit of savings. The outreach of microfinance in the war affected Northern and Eastern provinces of Sri Lanka are inadequate to meet the present needs.

The microfinance sector in Sri Lanka is not yet properly developed to provide protection against natural disasters. A survey carried out in 17 districts (out of 24 districts) in Sri Lanka reveals that only 8 percent of the households have obtained microfinance as a disaster risk mitigation strategy. Although there have been a number of microcredit programmes following tsunami, ground level evidence suggests that such programmes have not reached the communities actually in need. For instance, only 15 percent of the affected households in Southern and Eastern provinces of Sri Lanka have applied for loans following tsunami (IPS, 2006). In the Sri Lankan context, micro-credit cannot be seen as a common risk-management strategy following a disaster. IPS study (2006) reveals that most of the tsunami-affected households did not want to get into debt following the disaster situation. Better educated households were more likely to apply for loans following tsunami.

\section{Poverty Alleviation Programmes}

Since poverty and vulnerability are linked to each other, poverty alleviating programmes could also contribute to social protection. The largest social assistance programme in Sri Lanka, 'Samurdhi', aims at improving the nutritional status of poor families by direct financial assistance and to increase the income level of rural households through other programmes. Around 1.57 million families directly benefit through this programme (Central Bank of Sri Lanka, 2010). The Samurdhi insurance programme aims at reducing the vulnerability of the poor in terms of emergencies such as death, birth, marriage or illness in the family, but no provision has been provided to reduce their economic vulnerability to external shocks such as drought conditions, lack of water, environmental degradation, lack of access to public transport, poor education facilities, etc. (Salih, 2000).

\section{CONCLUSIONS AND POLICY RECOMMENDATIONS}

The above discussion follows the fact that the present system of social protection in Sri Lanka does not adequately provide protection to the vulnerabilities caused by natural disasters. The outreach of the present social protection programmes is very small and the present system does not sufficiently respond to the actual needs of the disaster-vulnerable groups.

The most notable fact is that the whole disaster risk management system is centred on immediate relief rather than assisting households to make them less vulnerable to such risks. The skewness towards relief based interventions is due to several reasons. Provision of immediate relief to disaster victims is the most visible intervention in providing economic security in the short run. Thus, the system should shift from a relief-based approach to a compressive approach which responds to long term recovery needs as well as short term needs. One of the policy priorities should be to restructure the crop insurance programme in Sri Lanka which has huge potential in assisting the disaster victims. Further research studies are required to understand the actual financial needs of communities following droughts and calamities, to identify their strengths and weaknesses and their aspirations and to identify different types of vulnerabilities following a disaster. Alternative disaster insurance instruments such as an index-based approach are being tested and implemented in various contexts, and the applicability of such alternatives in Sri Lanka also needs to be further studied.

Increasing the memberships of the programme has to be carried out using an innovative approach. Conducting proper awareness programmes is necessary to make disaster vulnerable groups to join the scheme. This could be facilitated through self-help groups. A variety of self-help groups are found in Sri Lanka including small farmer organizations, cooperative societies and various thrift societies who can coordinate and implement the insurance schemes efficiently. Through this approach, the insurance products can be made available at the doorsteps of the poor agricultural households and services could be delivered efficiently.

The analysis of coping strategies of households following natural disasters suggests that there is a huge demand for credit facilities following disasters. This type of programmes could be integrated into the Samurdhi programme, to provide better access to micro-credit facilities after disasters. The present social insurance programmes of Samurdhi could accommodate the insurance for natural disasters as well. In addition, introduction of alternative income sources during disaster situations could be a possible step in reducing vulnerability.

Finally, integrating programme that provide better security at natural disaster situations to the present system and restructuring the existing schemes would be much more appropriate in the Sri Lankan context. 


\section{References}

1. Abeyratne Bandara, W. M., 1997. Rural Poverty in Sri Lanka. In: Regional Expert Meeting on Capability-Building to Alleviate Rural Poverty, Beijing. [online] Available at: $<$ http://www.unescap.org/rural/doc/beijing_march97/> [Accessed September 2011].

2. Arunatilake, N., Wickramasinghe, K., Jayawardena, P., Weerakoon, D. \& Steele, P., 2006. Post Tsunami Reconstruction and Rehabilitation: Household Views on Progress and Process. Institute of Policy Studies, Colombo. [Online] Available at: <http://www.ips.lk/other_research/ tsunami_research/tsunami_research.html $>$.

3. Central Bank of Sri Lanka, 2010. Annual Report, Colombo: Central Bank of Sri Lanka.

4. Datt, D. \& Gunewardena, G., 1997. Some Aspects of Poverty in Sri Lanka: 1985 - 90. In: Policy Research Working Paper Series 1738. Washington DC: The World Bank.

5. Department of Census and Statistics, 2003. Poverty Statistics and Indicators for Sri Lanka. Colombo: Department of Census and Statistics.

6. Eriyagama, V. \& Rannan-Eliya, R. P., 2003. Assessment of the Farmers' and Fishermen's Pension and Social Security Benefit Scheme in Sri Lanka. Colombo: Institute of Policy Studies.

7. Holzman, R. \& Jorgensen, S., 2000. Social Risk Management: A New Conceptual Framework for Social Protection, and Beyond Social Protection. In: Discussion Paper No. 0006. Washington, DC: The World Bank.

8. Hoogeveen, J., Tesliuc, E., Vakis, R. \& Dercon S., 2004. A Guide to the Analysis of Risk, Vulnerability and Vulnerable Groups. Washington, DC: The World Bank.

9. Institute of Policy Studies, 2002. State of the Economy Report. Colombo: Institute of Policy Studies.

10. Institute of Policy Studies, 2006. 'Social Insurance and Social Assistance - Post Tsunami', review done for the Reconstruction and Development Agency, Unpublished report.
11. Mechler, R., Linnerooth-Bayer, J. \& Peppiatt, D., 2006. Disaster Insurance for the Poor? A Review of Microinsurance for Natural Disaster Risks in Developing countries. (A Pro Vention/IIASA study). [online] Available at: <http://www.preventionweb.net/files/2059_VL108400. pdf $>$ [Accessed September 2011].

12. Miranda, M. \& Vedenov, D. V., 2001. Innovations in Agricultural and Natural Disaster Insurance. American Journal of Agricultural Economics, 83(3), pp. 650-55.

13. Prowse, M., 2003. Towards a clearer understanding of 'vulnerability' in relation to chronic poverty. In: CPRC Working Paper No. 24. Manchester: Chronic Poverty Research Centre, University of Manchester.

14. Salih, R., 2000. Samurdhi Poverty Alleviation Programme (Draft), A paper prepared for the Social Security Division of the ILO, Geneva.

15. Senaka-Arachchi, R. B., 1998. Drought and Household Coping Strategies Among Project executing agenciessant Communities in the Dry Zone of Sri Lanka. In J. Twigg \& M. Bhatt eds., Understanding Vulnerability: South Asian Perspectives. London: Intermediate Technology Publications Ltd.

16. Tandon, A. \& Hasan, R., 2005. Conceptualizing and Measuring Poverty as Vulnerability: Does It Make a Difference? In: ERD Policy Brief No. 41. Manila: Asian Development Bank.

17. Tilakaratna, G., Wickramasinghe, U. \& Kumara, T., 2005. Microfinance in Sri Lanka: A Household Level Analysis of Outreach and Impact on Poverty. In: Poverty and Social Welfare Series No. 7. Colombo: Institute of Policy studies of Sri Lanka.

18. Vakis, R., 2006. Complementing Natural Disasters Management: The Role of Social Protection. In: Social Protection Discussion Paper No. 0543. Washington, DC: The World Bank.

19. World Bank, 2007. Sri Lanka Poverty Assessment, Engendering Growth with Equity: Opportunities and Challenges. In: Report No. 36568-LK. Poverty Reduction and Economic Management Sector Unit, South Asia Region. Washington, DC: The World Bank. 


\title{
Policies and issues in urban development in Sri Lanka: an examination of the inter-domain gaps
}

\author{
Jagath Munasinghe \\ Department of Town \& Country Planning, Faculty of Architecture, University of Moratuwa, Moratuwa
}

\begin{abstract}
This paper focuses on the issues with the current policies in urban development in Sri Lanka. Although much has been discussed on urban development related issues for many years, more attention of both the policy makers and the research community is needed since no significant improvements in connecting research, policy and practice are observed within the sector. Finding solutions for the problems at the roots of these issues is not an easy task, but a discourse on them is timely for improved awareness of those who are interested and affected. In order to contribute towards that, attention is drawn to the issues surging from the gaps in three areas: urban management, traffic management and adaptation to climate change effects, which are among the main concerns for present day urban development in Sri Lanka. In order to conceptualize the complex relationships between the policies, practices and research findings, the paper adopts a simple rational model of actors involved in the policy formulation processes which are divided into four mutually exclusive domains: research communities, interest groups, policy makers and the society. The paper highlights that many of the issues are surging from the gaps in between these four domains and hitherto the problems associated with the transfer of knowledge emanate from research findings, inevitable ground realities that are not reflected in policies, conflicts between the policy intentions and the social interests, and the perceptual differences among researchers, policy makers and the social groups.
\end{abstract}

Keywords: Interest groups, perceptual differences, policy formulation, urban development

\section{INTRODUCTION}

The current urban development trends and patterns in Sri Lanka (similar to many other countries) paved the way towards many complex issues, which in some way or the other are connected to policies. Although much has been discussed on these issues (eg: Perera \& Gunaratna, 1995; Kurukulasuriya, 1997; UDA, 1998; Gunaratne, 2006) for many years, greater attention of both the policy makers and research communities is required in the field as no significant improvements to the situations are observed to date. Finding clear cut solutions for all problems at the roots of these issues is far from a possibility, but a wider discourse on them is timely at least for the benefit of those who are interested and affected. In order to contribute towards that, this paper draws the attention to a few issues surging from the gaps, pertaining to research outcomes, ongoing practices and the policy formulation in the urban development sector in Sri Lanka.

As stated earlier, scholarly work on urban development issues are not rare, but a majority of these have focused upon specific aspects such as waste management (Perera, 2011), urban heat islands (Emmanuel, 1995), traffic management (Bandara, Lo \& Wong, 2006), etc. At the same time, these studies viewed problem situations more on technical grounds, divorced from the policy and the social context entangled with them. Hence, the attention paid on the impact of public policy and research on these issues and their implications on society at large is limited, despite the increasing importance for such studies. This study is an attempt to address this limitation in the urban development sector through a conceptual approach.

It is admitted that the relationships between scientific research, public policy and the society are sustained through complex processes, but not with technically simulative simple procedures (Weiss, 1991; Oh, 1997). Yet, the knowledge-driven or problem-solving based models, widely adopted in social sciences, are still useful to gain a general understanding of this relationship. Out 